\title{
Advanced methods of transportation and distribution of electrical power in smart power grids of railways
}

\author{
Evgeny Tretyakov ${ }^{1, *}$ \\ ${ }^{1}$ Omsk State Transport University, Karl Marx Ave., 35, Omsk, 644046, Russia
}

\begin{abstract}
The relevance of the work is determined by the need to improve the electrical distribution grids of railways on the basis of digital technologies. The article presents advanced methods of transportation and distribution of electric power in smart power grids of railways based on multi-agent control. The analysis of the power supply system for stationary railroad consumers was performed and advanced ways of their development were defined. These methods should provide increased speed, adaptive determination of restrictions on using electric power equipment, management of mode parameters, sectioning and power flow modes in electrical distribution grids, restoration of power supply after emergency events. The method of adaptive control of transportation and distribution of electric energy in the power supply system of stationary railway consumers is developed based on the hierarchical structure of IEC 61850. This method takes into account the coordination of managing and local controllers in the data exchange environment, the control results and the variable area of responsibility of controllers and their division according to their functional purpose based on the multi-agent approach. The method of power flow control was developed to reduce power losses, increase the capacity of transport channels and ensure the restoration of the normal mode of the electric network by reconfiguring it and controlling active elements based on graph theory. The method takes into account the expected daily load curve, limits on the demand for capacity by active consumers and the possibility of a closed mode of electrical network operation through controlled cross-sections. The simulation results presented on the test circuit have showed the feasibility and efficiency of the proposed approaches.
\end{abstract}

\section{Introduction}

Russian Railways holding company has the largest power grid complex in Russia, which provides electricity transmission services to third-party consumers. Electric power supply to third-party consumers amounted to 33.48 billion $\mathrm{kWh}$ in 2017 , which is $40.33 \%$ of the total consumption of railway transport.

Priority problems of low efficiency of the power supply system for stationary railway users are:

\footnotetext{
* Corresponding author: eugentr@mail.ru
} 
- high degree of depreciation of capital stock;

- low observability of the mode parameters;

- low level of providence with technical means for regulating the mode parameters and elements of automated control systems;

- insufficient capacity and overloading of cable and overhead lines and transformers;

- high actual losses and low quality of electric power;

- insufficient reliability of power supply to consumers.

Therefore, the technical re-equipment and modernization of the power equipment of the infrastructure of the power grid complex of the railways is one of the priority tasks facing Russian Railways.

At the current stage of the development of Russia's electric power systems, an urgent task is the development of principles, methods for the operation of intelligent energy systems with active elements and the means of controlling them.

Increasing the efficiency of the power supply system for stationary railroad consumers, including active elements, is possible due to the improvement of methods of economical transportation and distribution of electricity based on distributed intelligent automation systems and multi-agent management.

\section{Materials and methods}

Existing power supply systems for stationary railroad customers are made as hierarchical structures from source to load. They have low observability of mode parameters, poor equipping with linear regulators and elements of automated control systems [1].

Today, the supervisory control of the switches, which is usually performed by personnel, is the basis for controlling the mode parameters of the power supply system. It is represented as an automated dispatching system on the slide [2].

The automated system for managing the electricity supply of the railways includes five levels, headed by Transenergo, a branch of Russian Railways. Electrical power is mainly transmitted and distributed to third-party consumers through the power supply system of railways at the voltage levels MV2 and LV.

The requirements for advanced methods of managing transportation and distribution of electric energy in the power supply system for stationary railroad consumers should be coordinated with the strategy for the development of the electric grid complex of the Russian Federation, elaborated for the period up to 2030 [3]. They also should take into account the specifics of the construction of a power supply system for railways.

Required functional properties:

- ensuring reliability and quality of electricity;

- distributed accumulation and generation of energy;

- observability, manageability, information processing and decision-making system;

- self-recovery in emergency situations.

The main requirements for promising methods of economical and reliable transportation and supply of consumers:

- new control systems with two-way communication to provide operational and automatic control of power supply facilities;

- increased speed and accuracy of the monitoring system, which provides tracking of the regime, identification of emergency and unacceptable situations, measurement of current parameters of the regime of the power system and equipment;

- adaptive definition of restrictions on the use of electric power equipment;

- systems of distributed and hierarchical ways of collecting, processing and storing information; 
- emergency and regime automatics: control of mode parameters, partitioning and power flow modes in distribution networks, restoration of power supply after emergency events.

Based on the presented requirements, the methods of managing the power supply system were considered. Despite the fact that centralization in management is more profitable, with the increase of information flows it becomes significantly more complicated. Multi-agent approach involves the integration of centralized and decentralized management. The main distinguishing feature of the multi-agent approach is the set of decision-making centers (parallelization of information flows).

Some authors $[4,5]$ work on elaboration of a well-known method of situational control, using the theory of fuzzy sets and cluster analysis along with the method.

The electric substation (ESS) control system based on the multi-agent approach can be implemented according to IEC 61850 [6] and is built on a hierarchical principle with three main levels: the lower (technological process); average (cell attachments); upper (common substation).

Modern distribution networks of railway junctions are multiply connected, spatially separated hierarchical objects functioning in the conditions of variability of their structure, parameters and operating modes with power centers from traction or transformer substations of AO-Energo.

The following devices can serve as objects of control: OLTC of $110,35,10 \mathrm{kV}$ transformers; devices for longitudinal capacitive compensation; reactive power compensation devices; linear regulators and booster transformers; facts (flexible ac transmision system facts) devices; sources of distributed generation; energy storages; active consumers; switching devices.

The method of adaptive control of transportation and distribution of electric energy in the power supply system of stationary railroad consumers includes an architecture with distributed decision centers (controllers-agents-coordinators) based on measurements and high-speed analysis performed with the use of computing means powered by agent systems; required sensors of electrical and non-electrical values; local controllers of executive devices.

Local controllers (of active elements - electrical equipment) can work autonomously and receive data directly at the connection point or from the virtual network model, on the basis of their assigned goals and as part of the power management system, having received a task from the distribution controller to achieve a global goal. Managing controllers (Figure 1) serve as coordinating agents.

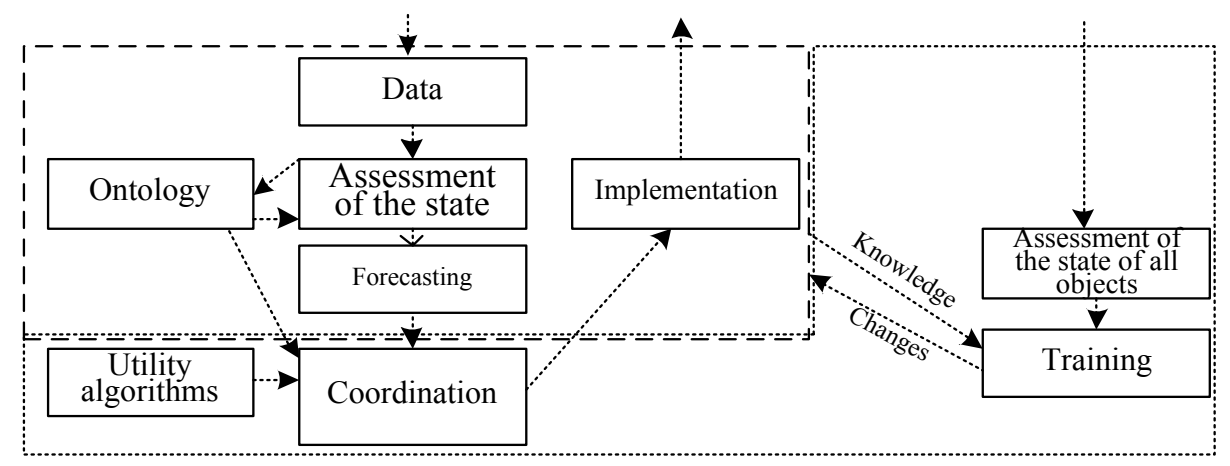

Fig. 1. Structure of managing controller.

Mathematically generalized description of multi-agent control system (MAS) [7]:

$$
M A S=(A G, E, P, S)
$$


where A $G$ - group of agents; $E$ - vector of set of environment states; $P$ - vector-function of state estimation; $S$ - vector-function of state change (behavior)

$$
P \times S \rightarrow A,
$$

$A$ - action, output alphabet;

$$
\begin{aligned}
& \tilde{S}_{i}(k)=\left[s_{1 i}, s_{2 i}, \ldots, s_{l i}\right]^{T} ; \\
& \tilde{A}_{i}(k)=\left[a_{1 i}, a_{2 i}, \ldots, a_{m i}\right]^{T} ; \\
& \tilde{E}_{i}(k)=\left[e_{1 i}, e_{2 i}, \ldots, e_{w i}\right]^{T} .
\end{aligned}
$$

Coordination is aimed at achieving a global goal or maximizing the impact of local control systems (agent controllers).

Controlling a group of agents

$$
\begin{aligned}
& \tilde{S}_{i}=f\left(S_{1}, A_{1}, \ldots, S_{N}, A_{N}, E\right), i=1, \ldots, N ; \\
& \tilde{E}_{i}=f\left(S_{1}, A_{1}, \ldots, S_{N}, A_{N}, E\right),
\end{aligned}
$$

is carried out subjected to the following constraints:

$$
\begin{aligned}
& G\left(S_{1}, \ldots, S_{N}, E\right) \leq 0 \\
& D\left(S_{1}, A_{1}, \ldots, S_{N}, A_{N}, E\right) \leq 0 .
\end{aligned}
$$

Local rules of self-organization (criteria for the effectiveness of agents - for the formation of the list of them) are described by the target function.

$$
J=\sum_{v=1}^{p_{\mu}} q_{i v}(\mu) \rightarrow \max _{i \in[1, \ldots, N]} ; n(\mu) \rightarrow \min ,
$$

where $q_{i v}(\mu)$ - assessment of the effectiveness of the agent's action performance; $n(\mu)$ number of agents, among the set of actions of which there are all the actions ensuring the achievement of the target task

When any agent controller cannot perform its work due to a failure, the nearest controller undertakes its functions.

The order of control over agents:

1) Obtaining the target task and forming a list of agents to solve it.

2) Adaptation of the algorithm for the work of agents to the current conditions.

3) Performing actions by agents in accordance with the algorithm.

To improve the reliability of teleinformation, state estimation methods are used, which allow filtering errors in measurements and calculate the missing current information.

The identification of the current mode is based on the assessment of the state of the electrical grid and includes the following:

- main topology - a set of nodes and links between them at the current time (grid graph and incidence matrix);

- parameters of the elements of the design scheme (resistance, conductivity of equipment, transformation coefficients, static load factors and generators, etc.);

- parameters of the design circuit mode (voltage and phase of node voltages, active and reactive power flows and currents in the branches (links), generation power and consumption graphs in the nodes, etc.).

In general terms, the procedure for evaluating the state of the power supply system consists in finding certain values of the mode parameters that satisfy the steady-state equation and correspond to the measured values. 
Topology analysis is performed by analyzing the measurements for the presence of line connection between two parts of the grid (agents).

MAS requires using a state estimation method based on the application of local measurements instead of volumetric centralized data, for instance, the method of asynchronous state estimation algorithms based on individual agents. Since the agent receives new estimates of the variables, it compares them with its own data based on the maximum credibility method, which consists in estimating an unknown parameter with a value that maximizes the probability of obtaining this sample collection from experiments.

The next subsystem of the managing controller (Figure 1) is an ontology and knowledge base in the power supply system.

The semantic network is used to represent the ontology: on the basis of class diagrams and constraints, all the knowledge needed by an agent for both individual work and interaction with other agents is described.

The ontology for the method under consideration contains concepts, attributes and relations applied to a particular object.

The ontology model is written as:

$$
O=(X, R, F),
$$

where $\mathrm{X}$ is a finite set of concepts (terms) of the subject area represented by the ontology; $\mathrm{O}$, $\mathrm{R}$ are finite set of relations between the concepts of a given subject area; $\mathrm{F}$ is a finite set of interpretation functions defined on concepts and ontology relations.

Ontology describes the concepts and relationships needed to describe models of objects of the subject area. The model describes stable combinations of concepts and relationships. The scene describes instances of concepts and relationships at a given point in time (as a set of facts)

Forecasting data for management purposes will improve the accuracy of the tasks being solved.

The results of previous measurements of power consumption, arranged in chronological order, can be considered as statistical information on the previous behavior, allowing to predict the further behavior of the system.

Forecasting the load that allows taking into account the influence of load behavior in the last preceding hours was performed by statistical extrapolation. The depth of the forecast is the hourly forecast for the day.

The method of multi-agent control is based on the coordination of distributed objects (Figure 2).

In terms of substance, coordination is aimed at harmonizing individual goals and behaviors of agents, when each agent improves or does not impair the value of its utility function, and the overall system improves the quality of the overall task.

The most common approaches to coordinating the group behavior of agents [7]:

1. Coordination by meeting the general rules of group behavior.

2. Coordination of behavior through the exchange of meta-information (negotiations) and rules for conflict resolution.

3. Teamwork for achieving a common long-term goal.

4. Coordination in a competitive conditions ("auction").

The algorithm that implements the auction procedure is iterative and includes a sequence of steps associated with the formation of the "cost" of achieving the goals of each agent, sorting them in order of increasing prices, determining the winner, re-forming the price array of agents, etc., until all targets will be distributed among the agents.

The first iteration

1. Task distribution.

2. Formation of a price array by agents $\left(k_{P}, k_{Q}\right)$. 
3. Determination of the effectiveness of the agent's actions. Ranking the array of their relations $\left(k_{P, Q} / a, b\right)$.

4. Choosing the best offers.

Subsequent iterations (when the tasks are not fully distributed (by better proposals)).
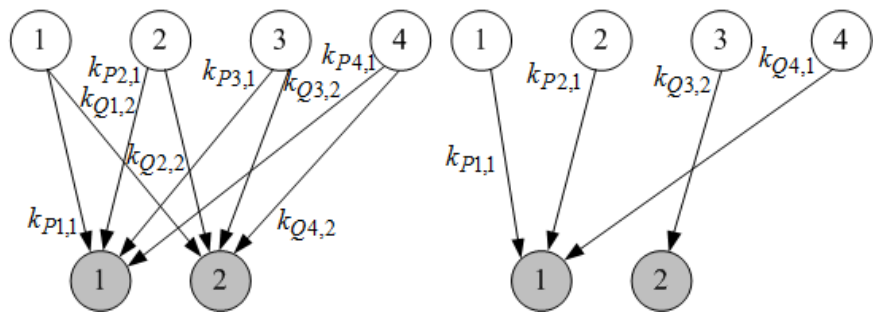

Fig. 2. Coordination of agents, where: $a$ - the initial configuration; $b$ - configuration after coordination.

Let us consider the section of the $6 \mathrm{kV}$ distributing grid of the power supply system of third-party railway users in the normal operating condition (Figure 3).

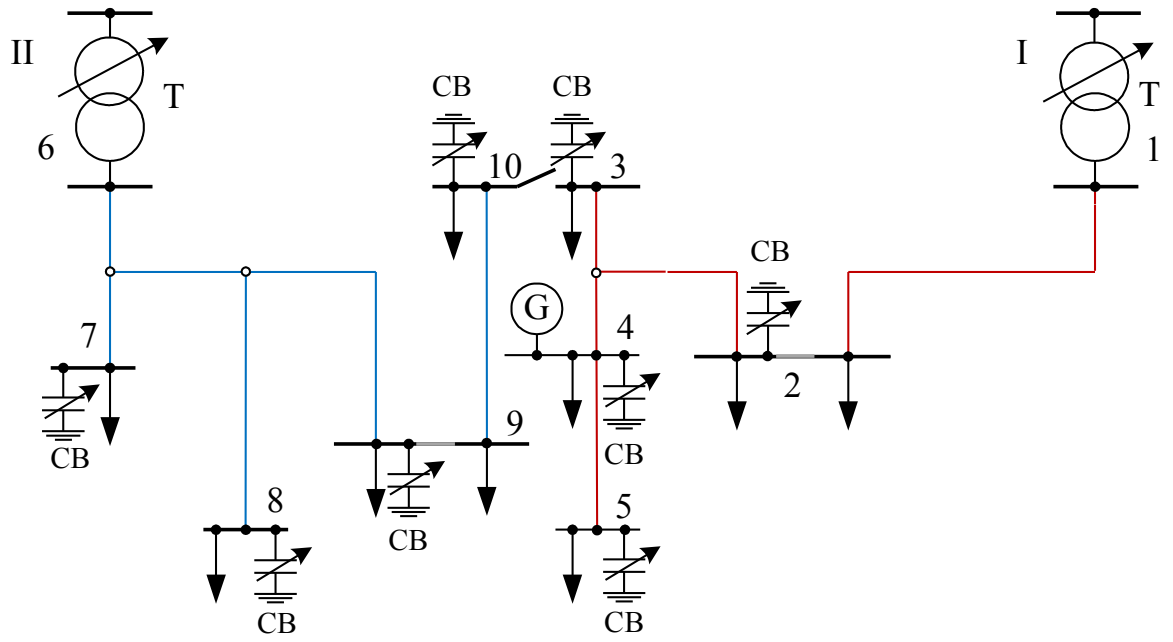

Fig. 3. Test electrical circuit.

Simulation modeling of coordinated voltage control in accordance with the proposed algorithm in the case of voltage deviation $\Delta U_{3}$ at the TS-3 (transforming station 3) of electric grid is performed in Matlab Simulink software.

The most effective sources and values of reactive power sources on buses TS 2, 4 and 5 and active power at TS 4 (equal to zero) were determined as a result of the ranking by decreasing the ratios $\left(k_{P 3} / a_{j 3}\right)$ and $\left(k_{Q 3} / b_{j 3}\right)$ and solving the optimization problem [8] to achieve the goal of control in the event of a voltage deviation $\Delta U_{3}$.

Since the solution of the optimization problem depends on the set of constraints and variables of several local controllers, it is solved iteratively, i.e. At each iteration step, controllers exchange updated values of their variables. In this case, the calculation is performed in three iterations and 0.2 seconds. For this example, if $\Delta U_{3}>190 \mathrm{~B}$, then the stabilization of the voltage on the bus 3 to a given deviation $\varepsilon$ is not ensured by local linear regulators. Fig. 4 shows the voltages on the TS buses fed from the CPU I, with the control at 
the power center (1), with coordinated control (2), in the initial mode (3) obtained as a result of simulation modeling.

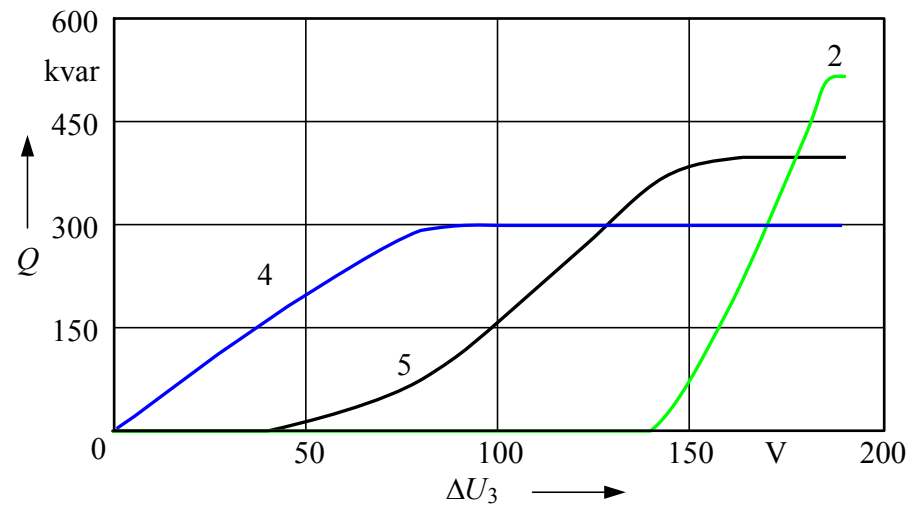

Fig. 4. The reactive power values of the control unit connected to the buses of TS 4, TS 5 and TS 2 fed from the CPU I.

Optimizing the mode of the electrical grid aimed at improving one of the parameters (for example, voltage) can cause the overloading of grid elements and reducing of its capacity. The distribution grid mode should be primarily permissible, or in other words, it should satisfy the conditions of reliability of power supply, capacity and quality of electric power [9-17].

Multi-agent control of power flows in the distribution network is carried out by:

- coordinated generation of active and reactive power;

- reconfiguration of the electrical network, including in closed mode with controlled connections;

- limiting the demand for electricity to consumers.

Management objectives:

- reduction of power losses;

- Restriction of overloads and increase of network capacity;

- Restoring of normal operation.

Algorithm for managing power flows based on their coordinated production. Target function for a minimum of costs for generation, transmission and distribution of electricity.

$$
f=\sum_{i \in G} \alpha_{i} \Delta P_{G i}+\sum_{i, j \in T} \beta_{i j} \Delta P_{T i j}+\sum_{i \in L} \gamma_{i} \Delta P_{L i}
$$

by condition

$$
\begin{aligned}
& \sum_{i \in G} P_{G i}=\sum_{i, j \in T} P_{T i j}+\sum_{i \in L} P_{L i} ; \\
& P_{G i}^{\min } \leq P_{G i} \leq P_{G i}^{\max } ; P_{T i j} \leq P_{T i j}^{\max } ; \\
& P_{G i}=P_{G i 0}+\Delta P_{G i} ; P_{T i j}=P_{T i j 0}+\Delta P_{T i j} ; \\
& P_{L i}=P_{L i 0}+\Delta P_{L i} ; U_{i}^{\min } \leq U_{i} \leq U_{i}^{\max }
\end{aligned}
$$

Where PGi, PTij, PL - generation power, power loss in the electrical grid, load power; $\alpha \mathrm{i}, \beta \mathrm{ij}, \gamma \mathrm{i}$ - coefficients of costs for generation, transmission and priority of the load.

It is more effective to solve the presented problem in accordance with graph theory by the methods of the shortest path; maximum flow [18]. The Dejkstra algorithm is a general procedure for sequentially updating the distance label until they satisfy the conditions for the 
optimality of the shortest path. The maximum flow (push-relabel) algorithm allows determining the maximum capacity of sections of the electrical grid.

The reconfiguration of the electrical network can be used for the following purposes:

- in normal mode to improve the economy of transmission and distribution of electrical power;

- restoring normal operation.

The methods for solving the problem of determining the optimal reconfiguration of an electrical grid are:

- selecting options;

- successive approximation;

- probabilistic;

- heuristic (preferably).

The reconfiguration target function in normal mode usually minimizes the loss of electrical power in the grids. In practice, the frequency of reconfiguration in normal mode is limited by the resource of switching devices and limiting the negative consequences of transients in the electrical grid. Reconfiguration in normal mode can be carried out from 2 times a year up to 2 times a day. The transfer of medium voltage electrical grids into closed mode through FACTS devices for optimal power flow redistribution is promising and advanced.

It is known that the circuits of electrical grids should have sufficient flexibility in terms of their topology and parameters, allowing the transfer of power in various modes, including repair and post-emergency.

Restoration of normal mode:

- reconfiguration to increase capacity (reduce overload);

- division of the grid for the partition of the damaged area.

Reconfiguration conditions:

- providing a balance of power, including reserve;

- exclusion of overloading of electrical equipment;

- elimination of unacceptable levels of voltage and frequency.

The division of the system into subsystems is based on weak links based on the sensor analysis of the electrical grid.

Management of power flows in closed circuit power grids (controlled AC transmission systems) instead of normally open points allows controlling the flow of active and reactive power and stabilizing voltages.

The simulation results showed that the use of controlled flexible alternating current transmissions contributes to a significant reduction in power losses, stabilization of voltages.

The management of power flows in the power grid based on the multi-agent approach is carried out by changing the power schemes (if possible), controlling the generation of reactive (active) capacity, and limiting the demand for electric energy by consumers. Along with limiting the power of consumers in abnormal modes, an approach with more careful ranking of consumers in terms of possible damage to their disconnection in real time and their flexibility in demand management (so-called active consumers) is proposed by the appropriate automation (disconnection).

Priority of the load is determined by ranking the consumers according to the demand price function at the time of shutdown.

\section{Results}

Advanced methods of transportation and distribution of electric power in smart power grids of railways are presented based on multi-agent control. The analysis of the power supply system for stationary railroad consumers was carried out and promising ways of their 
development were specified. The methods listed in the article should provide increased speed, adaptive definition of restrictions on the use of electric power equipment, management of mode parameters, partitioning and power flow modes in distribution networks, restoration of power supply after emergency events. The method of adaptive control of transportation and distribution of electric power was elaborated for power supply system of stationary consumers of railways. This method is based on the hierarchical structure of IEC 61850, which takes into account the coordination of managing and local controllers in the data exchange environment, control results and the variable responsibility zone of managing controllers and their functional division based on multi-agent approach. The promising method of power flow control is described, which is aimed at power loss reducing, increasing the transport capacity and ensuring the restoration of the normal mode of the electric network by means of reconfiguring and controlling the active elements based on graph theory. The method takes into account the expected daily load curve, the limitation on the active users' demand for power and the possibility of a closed mode of electric network operation through controlled sections.

\section{Discussion}

Today, electrical distribution grids of electric railways should be modernized not only by switching to digital data transmission technologies in secondary circuits, but also by creating a flexible management system for such grids in order to improve the reliability of power supply, the cost efficiency of transportation and distribution of electric power to ultimate customers. To implement the proposed approaches to the structure and management of such electrical distributing grids, they primarily should be observable and manageable, able to work in closed mode through controlled components of power electronics.

\section{Conclusions}

The elaborated method of adaptive control of transportation and distribution of electric energy in the power supply system of stationary railroad consumers, based on multi-agent control, will significantly improve the cost effectiveness of electrical power transportation and increase its quality at the new technological level.

The simulation results presented on the test electrical circuit showed the feasibility and effectiveness of the proposed approaches.

\section{References}

1. V.S. Pochayevets, Avtomatizirovannyye sistemy upravleniya ustroystvami elektrosnabzheniya zheleznykh dorog: uchebnik (UMTS ZHDT, Moskow, 2003)

2. O.V. Gribachev, Operativnoye upravleniye distantsiyey elektrosnabzheniya zheleznykh dorog: uchebnoye posobiye (UMTS ZHDT, Moskow, 2005)

3. Strategiya razvitiya elektrosetevogo kompleksa Rossiyskoy Federatsii (na period do 2030 goda), Sobraniye zakonodatel'stva Rossiyskoy Federatsii 14, 1738 - 1787 (2013)

4. A.V. Kryukov, V.P. Zakaryukin, Operativnoye upravleniye $v$ sistemakh elektrosnabzheniya zheleznykh dorog: monografiya (IrGUPS, Irkutsk, 2012)

5. A.V. Kryukov, V.P. Zakaryukin, A.V. Cherepanov, Izvestiya transsiba 3(19), 65 - 73 (2014)

6. Russian Federation Standard GOST R MEK 61850-2009 
7. S. Rassel, P. Norvig, Iskusstvennyy intellekt: sovremennyy podkhod (Izdatel'skiy dom Vil'yams, Moscow, 2006)

8. Ye.A. Tret'yakov, Pat. № 2587128 Rossiyskaya Federatsiya, MPK B60M 3/02, H02J 13/00, G05B 19/04. Sposob upravleniya sistemoy elektrosnabzheniya zheleznykh dorog № 2015103374/11 (2016)

9. A.G. Fishov, Sb. dokl. mezhdunar. nauch.-tekhn. konf., Ural'skiy fed. un-t 1, $91-97$ (2012)

10. S.T. Ismoilov, A.G. Fishov, Nauchnyye problemy transporta Sibiri i Dal'nego Vostoka 1-2, 302-305 (2014)

11. V.I. Panteleyev, L.F. Poddubnykh, Mnogotselevaya optimizatsiya i avtomatizirovannoye proyektirovaniye upravleniya kachestvom elektrosnabzheniya v elektroenergeticheskikh sistemakh: monografiya (SFU, Krasnoyarsk, 2009)

12. A.I. Seslavin, Ye.A. Seslavina, Issledovaniye operatsiy i metody optimizatsii: uchebnoye posobiye (UMTS ZHDT, Moscow, 2015)

13. M.V. Andreyev, N.YU. Ruban, I.S. Gordiyenko, Vserezhimnoye matematicheskoye modelirovaniye releynoy zashchity elektroenergeticheskikh sistem: monografiya (TPU, Tomsk, 2016)

14. N.I. Ovcharenko, Avtomatika energosistem: uchebnik (Izdatel'skiy dom MEI, Moscow, 2016)

15. H.B. Wu, C.Y. Huang, M. Ding, B. Zhao, P. Li, Journal of Modern Power Systems and Clean Energy 5(5), 504-511 (2017)

16. V.I. Panteleyev, A.N. Tulikov, Nauka. Tekhnologii. Innovatsii: Materialy vseros. nauch.konf. molodykh uchenykh 3, 175 - 179 (2006)

17. Russian Federation Standard GOST 32144-2013

18. S.V. Mitrofanov, L.A. Semenova, Modelirovaniye $v$ elektroenergetike: uchebnoye posobiye (OGU, Orenburg, 2015) 